\title{
Effect of corrosion degree on mechanical properties of reinforcements buried for 60 years
}

\section{Efeito do grau de corrosão em propriedades mecânicas de armaduras enterradas por 60 anos}
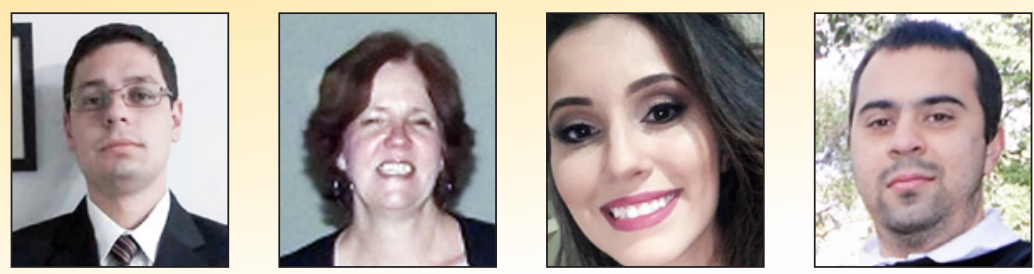

C. E. T. BALESTRA carlosbalestra@utfpr.edu.br

M. G. LIMA b

magdlima@gmail.com

A. Z. MENDES c adriane.zella25@gmail.com

R. A. MEDEIROS-JUNIOR c ronaldodemedeirosjr@yahoo.com.br

\begin{abstract}
This paper studies the influence of the corrosion degree calculated by the mass loss and by the smaller diameters on the yield strength, ultimate strength and final elongation. Reinforcements buried and naturally corroded for 60 years were studied. The mechanical properties of the protruding reinforcing steel were compared to reference bars, which also remained buried for 60 years, but without going through the corrosion process. Micrographs, besides the chemical composition and the characterization of the aggressiveness of the soil were realized. The micrographs and the chemical composition show the presence of pits in the reinforcements and sulfur contents for steel above the prescriptions of the time when the foundations were initially implement, respectively. The results also show that the effects of pitting corrosion on the mechanical properties of the naturally corroded bars may not be adequately expressed by the mass loss. This type of corrosion (pits) produces geometric variations in the cross sections along the length of the test specimens, generating stress gradients between successive sections. This has a noticeable impact on the mechanical properties of the reinforcements. In general, the effects of corrosion are more pronounced on the ductility of the reinforcement. Regarding the aggressiveness of the soil, high corrosion rates were identified in the reinforcement, even with the soil being classified as essentially non-corrosive.
\end{abstract}

Keywords: reinforcement corrosion, durability, mass loss, smallest diameter, corrosion degree, mechanical properties.

\section{Resumo}

Este artigo estuda a influência do grau de corrosão, calculado pela perda de massa e pelos menores diâmetros, sobre a resistência ao escoamento, limite de resistência e alongamento final em armaduras corroídas naturalmente. Essas armaduras permaneceram enterradas por 60 anos. As propriedades mecânicas das armaduras de espera foram comparadas às de barras de referência, que também permaneceram enterradas por 60 anos, mas sem sofrer o processo de corrosão. Foram realizadas micrografias, além da determinação da composição química e da caracterização da agressividade do solo onde as armaduras estavam enterradas. As micrografias e a composição química mostram a presença de pites nas armaduras e teores de enxofre acima das prescrições recomendadas para o aço na época de execução das fundações, respectivamente. Os resultados também mostram que os efeitos da corrosão por pites sobre as propriedades mecânicas das barras corroídas naturalmente podem não ser adequadamente expressos pela perda de massa. Esse tipo de corrosão (pites) produz variações geométricas nas seções transversais ao longo do comprimento dos corpos de prova, gerando gradientes de esforços entre seções sucessivas, que impactam de forma notória sobre suas propriedades mecânicas. De uma maneira geral, os efeitos da corrosão são mais pronunciáveis sobre a ductilidade das barras. Com relação à agressividade do solo, altas velocidades de corrosão foram identificadas nas armaduras, mesmo com o solo sendo classificado como essencialmente não corrosivo.

Palavras-chave: corrosão de armaduras, durabilidade, perda de massa, menor diâmetro, grau de corrosão, propriedades mecânicas.

Universidade Tecnológica Federal do Paraná, Toledo, PR, Brasil; 


\section{Introduction}

The limitation of tensile strength presented by concrete is supplied by means of the reinforcing steel, allowing the building of slender structures with greater spans. However, the introduction of reinforcement in concrete may result in degradation problems in reinforced concrete structures due to corrosion that, in advanced states, may lead the structure to ruin. In this sense, studies highlight that the maintenance and rehabilitation of structures degraded by corrosion involve significant financial amounts [1-4].

The effects of corrosion in reinforced concrete structures involve consequences to the mechanical properties of the bars, mainly due to a decrease of their transversal section and of the adherence between concrete and protruding reinforcing steel $[5,6]$. Besides, the corrosion products generate tensions in the radial direction to the axis of the bars that are not supported by the limited plastic deformation of concrete, leading to cracking and posterior displacement of the concrete cover [7-9].

The mechanism of corrosion leading to the degradation of the reinforcement has been an object of research in the whole world, however, the influence of natural corrosion on the mechanical properties of the reinforcement represent a smaller part of those studies $[6,10,11]$. It has been observed that most of the works regarding the evaluation of the mechanical properties of corroded rebars is about accelerated corrosion tests in laboratory environment. It must be highlighted that, depending on the methodology used to promote the reinforcement corrosion - salt chambers for instance - those works may not generate the formation of the passivating layer that cover the reinforcement inside the concrete due to the alkaline $\mathrm{pH}$ of the mean; this results in an uniform attack, and, in consequence, differences regarding the corrosion mechanism $[6,8,10$, 12-16]. In this context, the reinforcement corrosion by the action of chlorides is characterized as being by pits, since the chlorides have the capacity of breaking locally the existing passivating layer. In consequence, the corrosion is propagated in the pit, according to the stack active-passive in non polarized conditions [1, 10, 11]. Studies of Almussallan [12], Apostolopoulos et al. [10] and François et al. [8] may be mentioned among the researches contemplating the reinforcement corrosion made in laboratory. In the perspective of reinforcement corroded obtained from real structures, it is possible to mention studied from Palssom e Mirza [5], Papadopoulos et al. [17], Zhang et al. [16] and Balestra et al. [11].

The methodology used by Almussallan [12] consists in applying a current in steel bars embedded in concrete in order to accelerate the corrosion process. The author points to sudden fractures with corrosion degree over $12 \%$. Apostolopoulos et al. [10] submitted bars directly exposed to salt fog and also bars embedded in concrete exposed to the same mist. The authors highlight that comparing bars with the same corrosion degree, the bars immersed in concrete show a greater reduction regarding the yield strength and ductility and greater depth of pits than the ones directly exposed to salt fog. In the study of François et al. [8] were used bars extracted from reinforced concrete beams exposed to an environment with chlorides. Results show a decrease of mechanical properties due to corrosion and lack of indication of necking in the corroded bars. Palssom and Mirza [5] used 103 samples of reinforcement from a Canadian bridge deck slab, demolished due to corrosion problems of the reinforcement due to the use of deicing salts. Papadopoulos et al. [17] carried out tests of tensile strength in 96 test specimens extracted from hundreds of years' old edifications in Greece. Recently, study of Zhang et al. [16] compared the behavior to tensile strength and the fatigue or protruding reinforcing steel in edification with more than 30 years in China and Balestra et al. [11] evaluated the effect of the corrosion degree in the effective and nominal resistance of protruding reinforcing steel naturally corroded.

Generally, independently if the corrosion method of bars is accelerated in laboratory or under natural conditions, the mentioned studies point for a decrease in values regarding yield strength, ultimate strength, final stretching and ductility, as the loss of mass of the corroded rebar increases.

The influence of the transversal section over the mechanical properties of the reinforcing steel is presented in studies from Apostolopoulos [18] and Zhu and François [19]. In the first study, bars were corroded in a salt fog chamber until 120 days. Results show a progressive variation of the mechanical properties of the bars as the diameter of bars is reduced due to corrosion. In the second study different patterns of corrosion where analyzed. Results show that asymmetric forms of the corroded sections, with greater eccentricity values, had the lower values of final stretching when compared to sections symmetrically corroded. Besides, in those asymmetric sections, the eccentricity increased the concentration of tensions in the transversal sections, drastically decreasing the final elongation of bars.

In face of what was exposed, to provide mechanisms allowing for evaluating the relationship of corrosion with the mechanical properties decrease of the reinforcement, in order to verify the remaining carrying capacity of a degraded reinforced concrete structure is necessary, with the objective of determining security levels. Thus, given the existence of few studies using naturally corroded reinforcement, this paper has the objective of presenting results regarding the effects of the corrosion degree, expressed by the loss of mass and by the smaller diameters, over the mechanical properties of protruding reinforcing steel naturally corroded in the soil during decades, coming from an old set of foundations executed in reinforced concrete. For that, tensile tests in specimens removed from those protruding reinforcing steel were made.

This set of foundations was composed by (i) piles; (ii) foundation blocks in reinforced concrete, with protruding reinforcing steel with original nominal diameters of 5/8" $(15.88 \mathrm{~mm})$ and concrete with compressive strength of $12 \mathrm{MPa}$; and (iii) protruding reinforcing steel destined to the link between the foundation blocks and the pillars of the building, with original nominal diameters of 5/8" (15.88 $\mathrm{mm}$ ) and $3 / 4 "(19.8 \mathrm{~mm})$. The set of foundations belongs to the "Technological Institute of Aeronautics (ITA)", located in São José dos Campos, Brazil, and remained buried during a period of 60 years, because there was no possibility of building a part of the edifications during the decade of 1950.

When works resumed, problems such as detachments between blocks and piles and the corrosion of protruding reinforcing steel were verified "in loco", which made impossible to use those old foundations. Thus, the old foundations were discarded, and the protruding reinforcing steel and a block of foundation being collected to researches.

It is important to highlight that the protruding reinforcing steel remained buried in the soil during decades, being its corrosion 
process natural, in other words, without the influence of procedures accelerated in laboratory that may not properly reflect the strength expected from naturally corroded bars $[11,16]$. This fact allows a realistic quantitative analysis of the effects of corrosion determined by means of gravimetric loss and decrease of the diameter of the bars over the mechanical properties of the protruding reinforcing steel.

A characterization analysis of the soil, as a corrosive medium was executed. Besides, also part of the scope of this work is the determination of the chemical characteristics of the protruding reinforcing steel and an analysis by microscopy, in order to observe the type of corrosion (morphology).

\section{Characterization of the soil as an aggressive medium regarding corrosion}

The soil is presented as one of the more important and complex aggressive mediums to structures, due to the joint actuation of several factors, such as, the variation of soil composition, the moisture present and the activity of microorganisms [20]. The interaction of the factors interfering in the corrosion of metals in soil makes its performance to have characteristics of distinct durability in different regions [21].

The main factors influencing the corrosiveness of the soil are: aeration, resistivity, presence of ions (chlorides and sulfates), moisture, $\mathrm{pH}$ and microorganism activity [22-25].

Among those factors, Balestra et al. [11] state that resistivity is a parameter indicating the corrosiveness of the soil, obtained by means of field tests. In this sense, the standard ASTM G57-06 [26] establishes methodological criteria for determining the soil aggressiveness resistivity according to the method of four electrodes by Wenner.

Regarding the criterion used to evaluate the soil aggressiveness in field, NACE [27] establishes ranges of values for characterizing the soil aggressiveness, according to its resistivity. According to this classification, presented in Table 1, soils with resistivity over $20000 \Omega . c m$ are characterized as essentially non corrosive, while soils with resistivity below $700 \Omega . c m$ are extremely corrosive.
Table 1

Classification of soil aggressiveness according to NACE [27]

\begin{tabular}{|c|c|}
\hline Soil resistivity $(\Omega . \mathbf{c m})$ & Evaluation of corrosivity \\
\hline$>2000$ & Essentially non-corrosive \\
\hline $1500-2000$ & Averagely corrosive \\
\hline $1200-1500$ & Moderately corrosive \\
\hline $1000-1200$ & Corrosive \\
\hline $700-1000$ & Highly corrosive \\
\hline$<700$ & Extremelly corrosive \\
\hline
\end{tabular}

\section{Experimental program}

\subsection{Characterization of local and soil}

The materials used for obtaining the specimens for the tensile test are from protruding reinforcing steel, not corroded, removed from the lower face of a foundation block (reference) and of protruding reinforcing steel in process of natural corrosion. It must be highlighted that this protruding reinforcing steel had 60 years. The protruding reinforcing steel remained buried in process of natural corrosion in the soil during this period, while the protruding reinforcing steel of the foundation block (lower region of the block) remained protected by the concrete and did not have corrosion. Figure 1 shows a scheme of the location of the old foundations.

The soil where the foundations were present is characterized by the presence of silt and clay, with a predominant reddish color, indicating the presence of iron oxides. The chemical characteristics of the soil are presented in Table 2. Two samples were collected for characterization of the soil, being possible to observe a $\mathrm{pH}$ near neutral for sample 1 and a basic $\mathrm{pH}$ in sample 2. Table

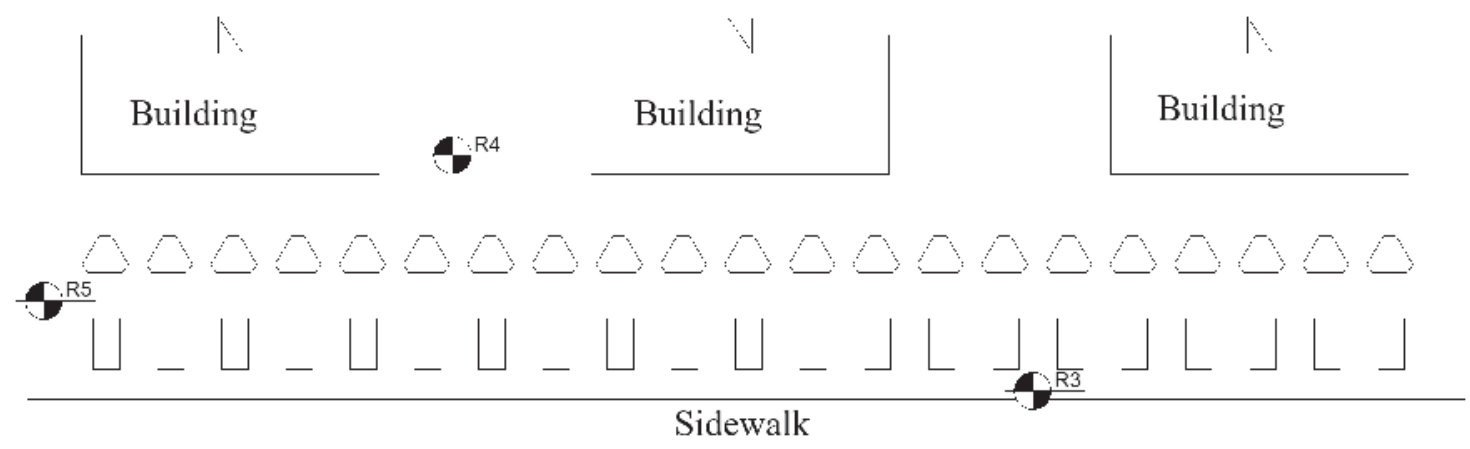

Street

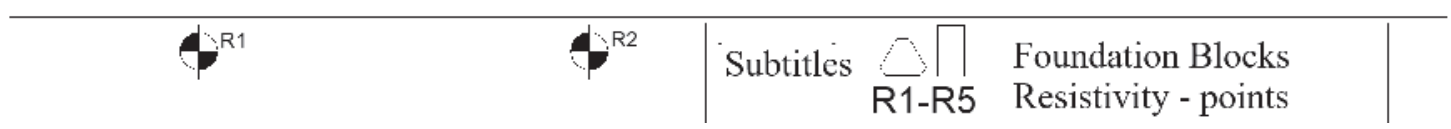

Figure 1

Scheme of the location of old foundations and points of determination of soil resistivity (R1-R5) 
Table 2

Chemical characteristics of soil

\begin{tabular}{|c|c|c|}
\hline Parameter & Sample 1 & Sample 2 \\
\hline $\mathrm{pH}$ & 7,10 & 8,97 \\
\hline Sulfides (\%) & 0,004 & 0,004 \\
\hline Calcium oxides (\%) & 0,31 & 0,92 \\
\hline Magnesium oxides (\%) & 0,06 & 0,07 \\
\hline
\end{tabular}

2 also reveals a greater presence of calcium oxide in sample 2 . The amounts of sulfides and magnesium oxide found were similar between the samples.

The presence of chlorides was evaluated by means of tests in concrete samples taken near the upper face of the concrete block collected for studies, since the evaluation of chlorides straight in soil is a complex activity, because the water from rain penetrates the soil and may carry and unequally distribute the chlorides present in it. Thus, samples of concrete powder were collected in seven points of the block by making holes with diameter equal to $19 \mathrm{~mm}$, until a depth of $20 \mathrm{~mm}$ in the proximities of the concrete surface. The powder material was collected and analyzed by titration using a solution of ammonium thiocyanate $(0.05 \mathrm{M})$, as described in the procedure of RILEM TC 178-TMC [28]. The titration is conducted until the solution of thiocyanate produces a brownish color that does not disappear with shaking, thus indicating the presence of chlorides (Figure 2).

Besides that, an analogical terrometer was used to determine the soil resistivity in five points (R1-R5) in the place where the foundations were present (Figure 1). In each point two measurements were made, varying the distance between piles ( 5 and 10 meters). The values of soil resistivity are presented in Figure 3.

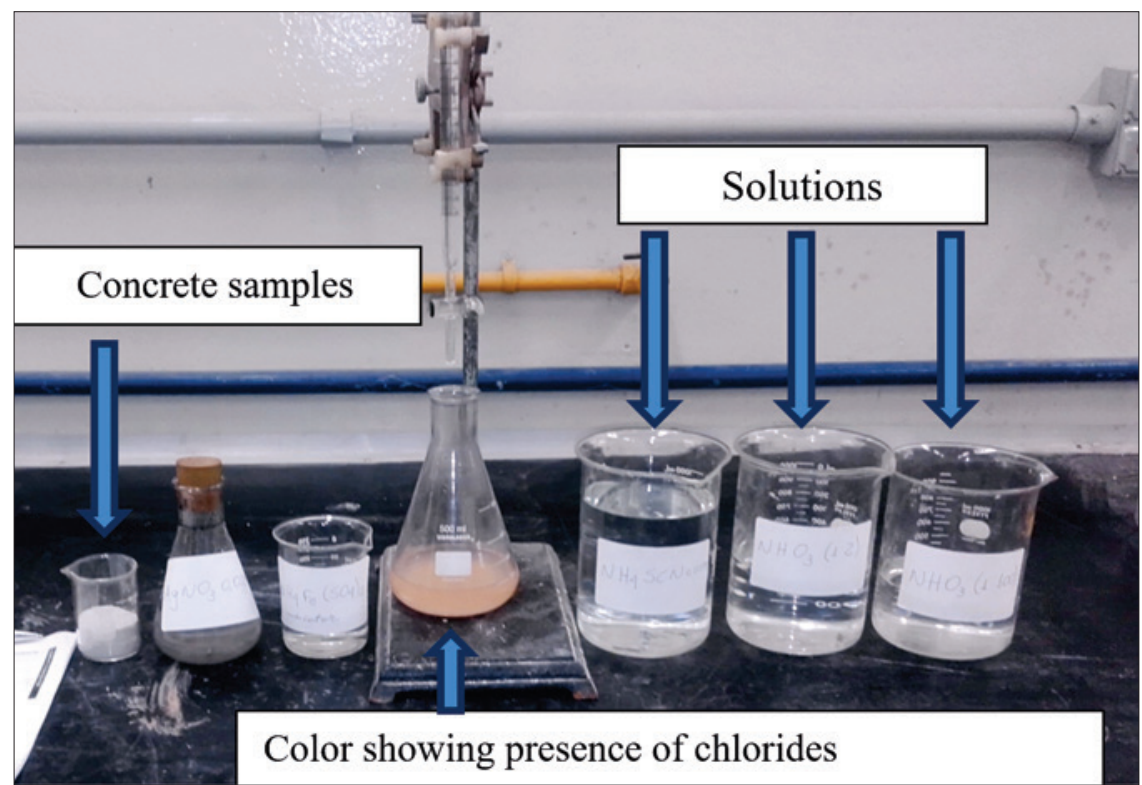

\section{Figure 2}

Analysis for verification of the presence of chlorides in foundations

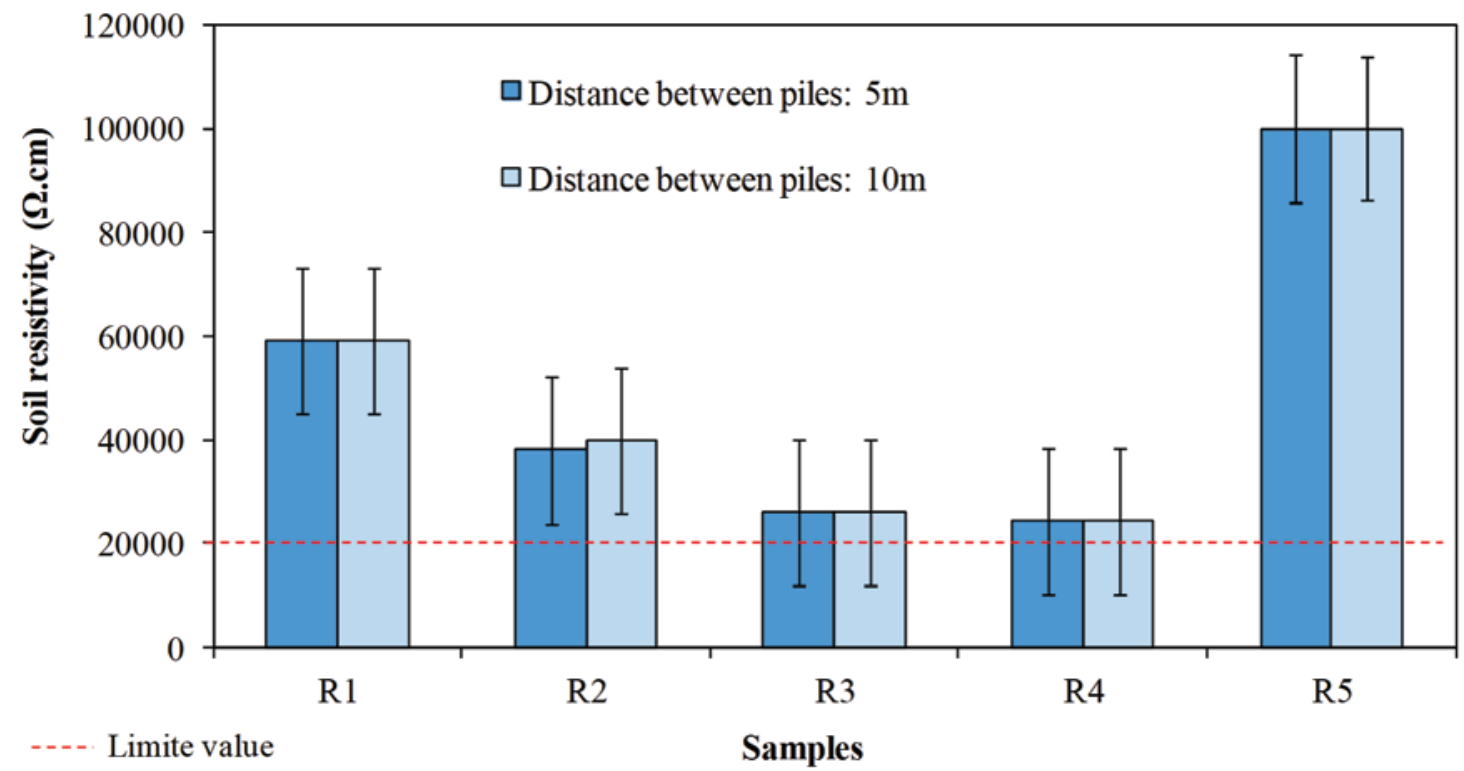

Figure 3

Soil resistivity at the study site 


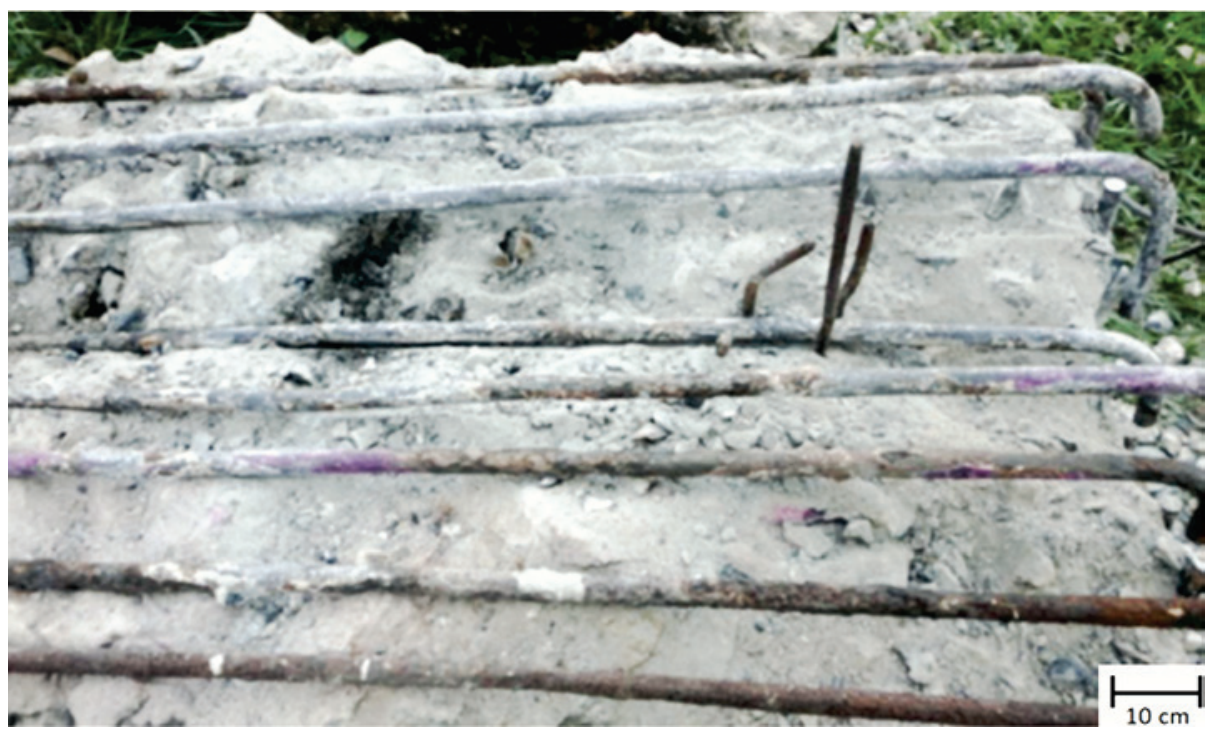

\section{Figure 4}

Full exposition of the foundation block protruding reinforcing steel

The results of resistivity presented, with values over $20000 \Omega . c m$, classify the soil as essentially non aggressive for both distances between piles ( 5 and 10 meters). Besides, it is possible to observe that the distance between piles did not cause great variations in resistivity values obtained by a single point.

\subsection{Analysis of the reinforcement}

\subsubsection{Reinforcement of the foundation block (reference - non corroded)}

A concrete breaker was used for extracting the reinforcement

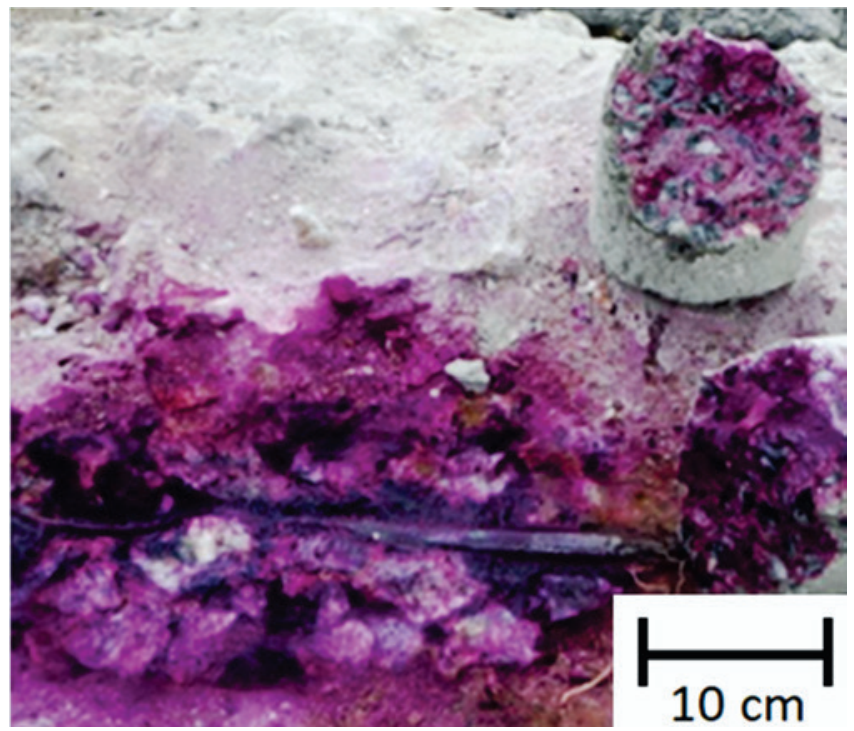

\section{Figure 5}

Geometry of reference cross-section for case study present in the foundation block, and a grinder for cutting the bars. A set of eight bars with original diameters of 5/8" (15.88 mm) was obtained, as observed in Figure 4. It must be highlighted that in this procedure, the integrity of the bars was preserved, taking care to avoid the tip of the equipment making contact with the bars, causing deformation, fissures or eventual ruptures, damaging the samples.

The alkalinity of the medium where the bars were inserted inside the foundation block was verified by means of pulverization of a phenolphthalein solution over the surface of the concrete of the recently fractured block, as recommended by EN14630 [29]. This way, the alkalinity of the medium was verified by the pink carmine color, as observed in Figure 5. The pink carmine color of the indicator means that concrete has $\mathrm{pH}$ over 10 . This way, considering that the protruding reinforcing steel remained protected by the concrete against corrosion, a fact that can be verified both visually as by means of pulverization of the solution of phenolphthalein, the mean values of the mechanical properties of those test specimens were taken as reference values for comparing the mechanical properties of the test specimens coming from protruding reinforcing steel. It is also highlighted that the reinforcement of the blocks used as reference were extracted from the lower part of the foundation block, thus, protected against the action of chlorides when compared with the protruding reinforcing steel of the upper part of the block.

Brazilian standards NBR 6892 [30] and NBR 7480 [31] prescribe that the minimal length where the stretching of the test specimens is determined must be 10 times its nominal diameter. This way, with the diameter of the bars used in this study equal to $15.88 \mathrm{~mm}$, the minimum dimension of test specimens used in this study was defined as $330 \mathrm{~mm}$, with $160 \mathrm{~mm}$ destined to the measurement of stretching.

Thus, having defined the minimum dimensions of the test specimens, the most rectilinear parts of the reinforcement taken from foundation blocks were marked and cut. Following this procedure, five test specimens were obtained (BL1-BL5). 
Table 3

Chemical composition obtained in spectrometry test

\begin{tabular}{|c|c|c|c|c|c|}
\hline \multirow{2}{*}{ Face } & \multicolumn{4}{|c|}{ Element } \\
\cline { 2 - 6 } & Carbon (\%) & Silicon (\%) & Manganese (\%) & Phosphorus (\%) & Sulfur (\%) \\
\hline 1 & 0,103 & 0,023 & 0,385 & 0,034 & 0,030 \\
\hline 2 & 0,106 & 0,025 & 0,385 & 0,034 & 0,031 \\
\hline
\end{tabular}

The choice of test specimens from the most rectilinear parts of the reinforcement is needed in order to avoid detours along the axial axis of them, which may influence in the tensile test. In parallel, a spectrometry test of optical emission was made in order to determine the main chemical species present in the bars. A bar segment was cut and its two faces were analyzed regarding the percentage of carbon, silicon, manganese, phosphorous and sulfur. The results of spectrometry are displayed in Table 3. The content of iron identified in both samples was $99.3 \%$

Mills et al. [32] state that for the steels of that time, with $0.10 \%$ of carbon in their composition, manganese should be placed in a range between 0.30 to $0.40 \%$. Clark [33] states that the proportion of silicon found in steel, generally, was in a range from 0.10 to $0.30 \%$ and, besides that, the proportion of sulfur and phosphorous should be limited to $0.015 \%$ and $0.05 \%$, respectively. However, results from Table 3 show that the content of sulfur and silicon is not according to limits described at the time, providing an indicator regarding a deficient quality control in the production of the bars. In this context, Souza [34] highlights that the presence of excess of sulfur negatively impacts the mechanical properties of the steel, reducing it ductility. Sulfur, when combined with iron, creates the iron sulphide (FeS) that has a lower fusion point regarding the steel,

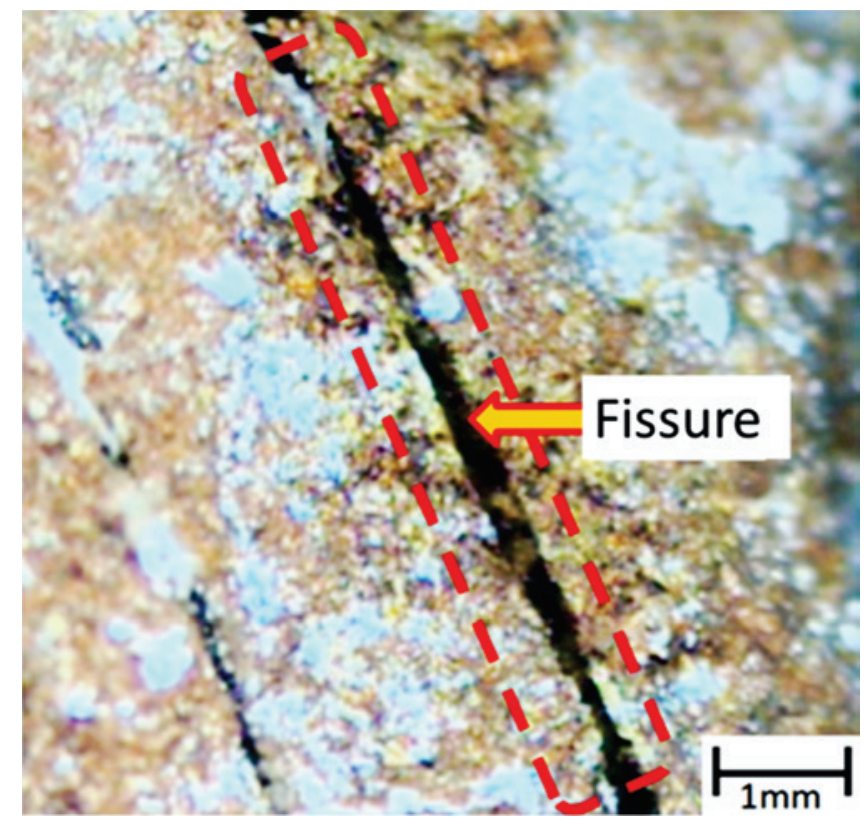

Figure 6

Fissure observed on the surface of one of the foundation block protruding reinforcing steel besides being located in the contour of grains. This fact may cause the fragility of the steel during stages of mechanical conformation, resulting in fissures. This behavior was observed in bars studied in this paper. Figure 6 shows a fissure identified in a discharged segment of bar, obtained from protruding reinforcing steel of the foundation block.

\subsubsection{Protruding reinforcing steel (corroded)}

Regarding the protruding reinforcing steel, bars with original nominal diameter of 5/8" (15.88 mm) where collected from the upper faces of the foundation blocks. For that, a grinder was used for cutting and collecting the bars. This procedure was executed as much closer to the upper surface of the blocks as possible, in order to get greater possible lengths of the bars. It is worth to highlight that in most of the cases, the protruding reinforcing steel was directly recovered by local soil; however in some cases, masonry boxes without caps or bottoms were built for mew the protruding reinforcing steel. In this case, the masonry boxes were built around the protruding reinforcing steel and filled with sand for mew the bars. Figure 7 shows a detail with the exposition of protruding reinforcing steel after opening one of those boxes.

The protruding reinforcing steel was originally folded before being

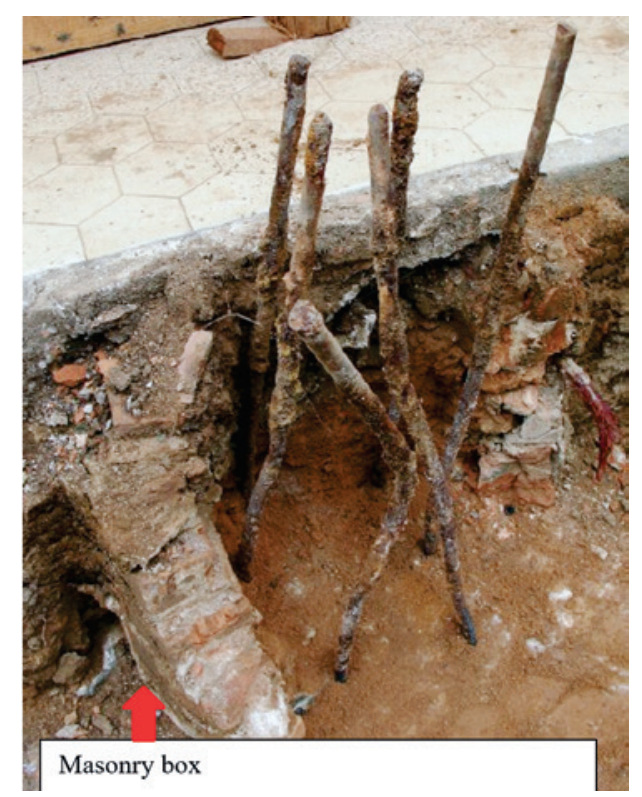

Figure 7

Exposure of some protruding reinforcing steel after opening the masonry box 


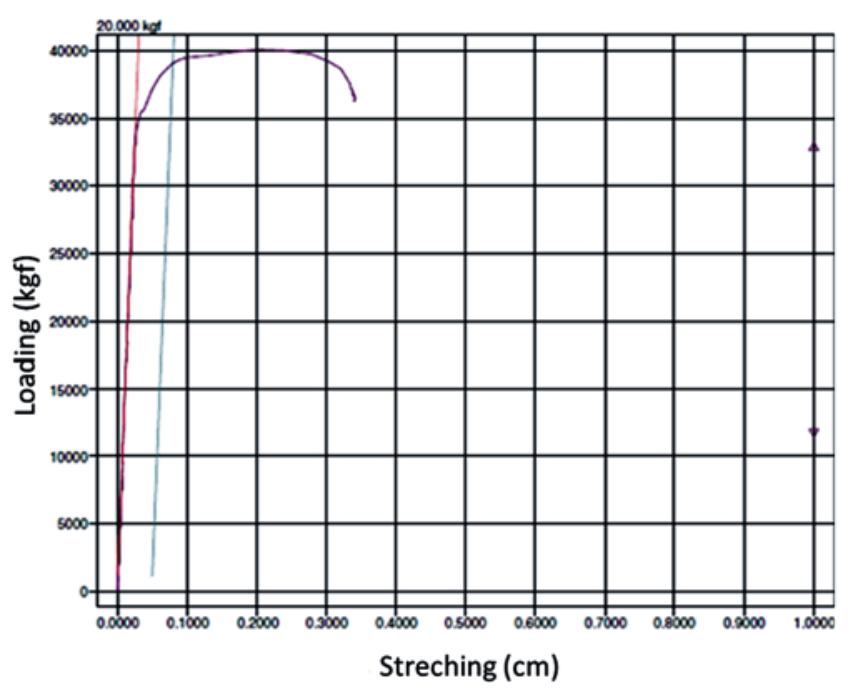

Figure 8

Diagram loading versus stretching - illustrative example of a test body

buried, having deviations along the length. With that, were selected the rectilinear lengths of the bars for extraction of the test specimens for the tensile test, observing prescriptions from NBR 6892 [30] and NBR 7480 [31] and the minimum adopted dimensions, as previously described. This measure aims to ensure that the effects from tortuosity of the bars have no influence on the results of the tensile test.

Thus, bars able to extraction of test specimens were marked, cut and submitted to a procedure of chemical cleaning using hexamethylenetetratramine, according to standard ASTM G1 [35]. A solution of hydrochloric acid (1:1) was prepared, adding $3.5 \mathrm{~g}$ of Hexamethylenetetramine. The test specimens coming from the protruding reinforcing steel were immersed in this solution during a period of 10 minutes (temperature $=23^{\circ} \mathrm{C}$ ) for removing corrosion products adhered to the surface of the test specimens. Those 20 minutes characterize 1 cycle. Thus, at each cycle, the test specimens were removed from the solution, washed in running water, dried with a cloth, and had their mass determined. The pickling process continued until it was not possible to observe variations over $0.1 \mathrm{~g}$ or mass between consecutive pickling cycles, which happened in approximately 5 cycles.

Then, the extremities of the test specimens were analyzed, discharging the test specimens that had deformations or accentuated corrosion in places destined to fix them in the claws of the universal machine. This measure aims to warrant that the rupture of the test specimens does not happen in these places, harming the tensile test. After this screening, twenty test specimens (PB1PB20) were obtained. A visual inspection over the surface of the test specimens, besides microphotographs, using an optical microscope of 10x, were made aiming to identify the existence of pits in the surface of the protruding reinforcing steel.

The determination of the smaller transversal section of the test specimens was made using a micrometer that has conical tips with precision of $0.004 \mathrm{~mm}$. In this procedure at least 35 measurements along the test specimens were made, being the small- er measured value corresponding to the smaller diameter of the analyzed test specimens. This determination aims the calculation of the corrosion speed in soil of the protruding reinforcing steel, according to Equation 1 [36], the number of years that the bars were buried being equal to 60 years. The corrosion speeds of soil were compared with the value proposed by CEMCO [37], where greater corrosion levels are observed when corrosion speed is over $0.010 \mathrm{~mm} / \mathrm{year}$.

$\mathrm{V}_{\text {corr. }}=\left[\left(\phi_{\mathrm{x}} / 2\right) / n\right]$

Where: vcorr = corrosion speed $(\mathrm{mm} /$ year $) ; \phi x=$ the greater loss of section measured in the bar $(\mathrm{mm})$; and $\mathrm{n}=$ number of years that the bar remained buried (years).

Besides the method for determining the corrosion speed by means of smaller diameters, the corrosion degree $(G)$ was also determined by means of the mass loss, expressed according to the percentage difference between original mass (Mo) of the protruding reinforcing steel, considering the original diameter $(15.88 \mathrm{~mm})$ and the specific mass of steel $\left(7.85 \mathrm{~g} / \mathrm{cm}^{3}\right)$, and the mass determined after the procedure of chemical cleaning (Mc) [11].

\subsubsection{Tensile test}

The test specimens were submitted to tensile tests in a universal machine of $20,000 \mathrm{kgf}$ of capacity, according to prescriptions from NBR 6892 [30], with tension values expressed according to the original cross-section area of the test specimens. Results of the mean of values obtained regarding yield strength, ultimate strength and final stretching of the test specimens BL1 to BL5 were used as reference parameters for comparing with results obtained from test specimens PB1 to PB20. Figure 8 shows a diagram of loading versus elongation of a typical test specimen used in this study. In this case, as determination of the flow baseline was not graphically clear, yield strength was calculated considering the plastic deformation of $0.2 \%$ [30]. Resistance limit was calculated according to the maximum load supported by the test specimens.

\section{Results and discussion}

\subsection{Mechanical properties of the reinforcement of the foundation block (BL1-BL5)}

The values of mechanical properties of the reference test specimens BL1-BL5 are presented in Figure 9, their mean values equal to: $267 \mathrm{MPa}( \pm 6 \mathrm{MPa}), 361 \mathrm{MPa}( \pm 6 \mathrm{MPa})$ and $30 \%( \pm 0.7 \%)$, corresponding to the yield strength, ultimate strength and final elongation, respectively. Those values will be used as reference to be compared with the corroded protruding reinforcing steel in this paper. It was not possible to determine the elongation of test specimen BL1 due to a problem in the used extensometer, this being replace for the continuity of the tests. It is possible to observe that test specimens BL1-BL5 had closer values regarding the measured mechanical properties, with standard deviations relatively small compared with absolute values. 


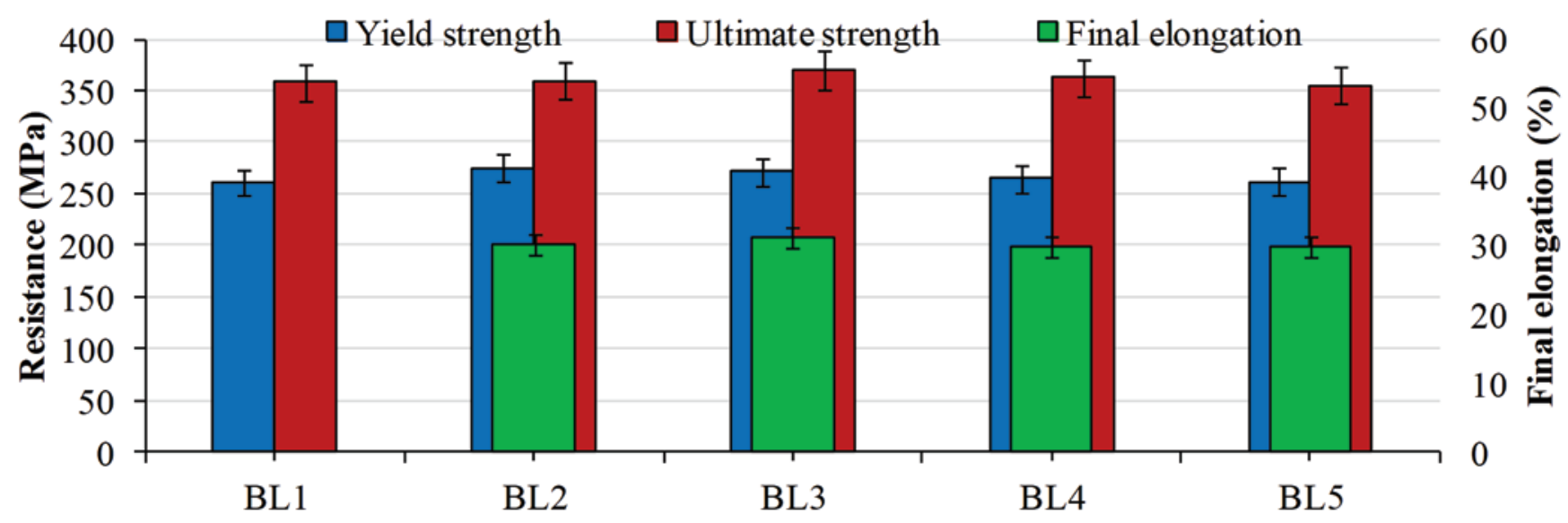

Figure 9

Specimens

Yield strength, ultimate strength and final elongation of test specimens BL1-BL5

\subsection{Protruding reinforcing steel}

\subsubsection{Corrosion speed in test specimens PB1-PB20}

The corrosion speeds of test specimens PB1 to PB20, calculated from the smaller diameters (Eq. 1) are shown in Figure 10, where points above the straight line of the graph have high corrosion speeds according to methodology proposed by CEMCO [37].

First of all, it is possible to observe in Figure 10 that all test specimens had high corrosion speed, according to criterion described by CEMCO [37]. Some test specimens had values dissonant from the average behavior, such as, bars PB 16 and PB 20. In this case, the protruding reinforcing steel from where those test specimens were taken remained closed in masonry boxes, built to mew them. Thus, a part of the bars remained in contact with the sand of the box and another part in contact with the clay from the local soil. This fact triggered the emergence of differential aeration stacks, favoring the corrosion process and, in consequence, contributing to raise the corrosion speeds. This behavior is in according to literature [38].

The analysis of Figures 3 and 10 result in an interesting observation. Even if the soil of the place was classified as essentially non corrosive (Figure 3), high corrosion speeds were obtained (Figure 10), demonstrating that expressing the corrosiveness of the soil only using the criterion of measuring its resistivity may not properly represent its aggressiveness with buried protruding reinforcing steel. Thus, other facts must also be taken into consideration in order to better describe the aggressiveness of soil, such as aeration, moisture, $\mathrm{pH}$, presence of microorganism activity, and others. Even if all values lead to high corrosion speeds, results presented in Figure 10 by corroded protruding reinforcing steel where very diversified. The mean corrosion speed measured was $0.0246 \mathrm{~mm} /$ year, however with a standard deviation of $0.0089 \mathrm{~mm} /$ year, representing a coefficient of variation of $36 \%$. This is a reflex of the characteristics of heterogeneity of the soil, as also discussed by Norhazilan et al. [20].

\subsubsection{Analysis of pits presence in test specimens PB1-PB20}

Figure 11(a) shows the image of a pit with depth of $4 \mathrm{~mm}$ obtained by means of visual analysis in a test specimen, while Figure 11 (b) shows a microphotography obtained from one of the test specimens from the protruding reinforcing steel, where it is possible to observe the presence of pits, by means of dark dots indicated in the image. The pits were verified in all test specimens of protruding reinforcing steel. There were no pits identified in the test specimens of the lower region of the foundation block (BL1-BL5, reference). The protruding reinforcing steel was collected near the edifications already existing in ITA since the decade of 1950. Thus, it was verified in local that the lack of draining systems of surface water, together with the use of cleaning products based in chlorine for maintenance and cleaning of those existing buildings, denoted an external source of chlorides in soil that contributed for the emergence of pits in protruding reinforcing steel. This affirmation is supported by analysis made to verify the presence of chlorides

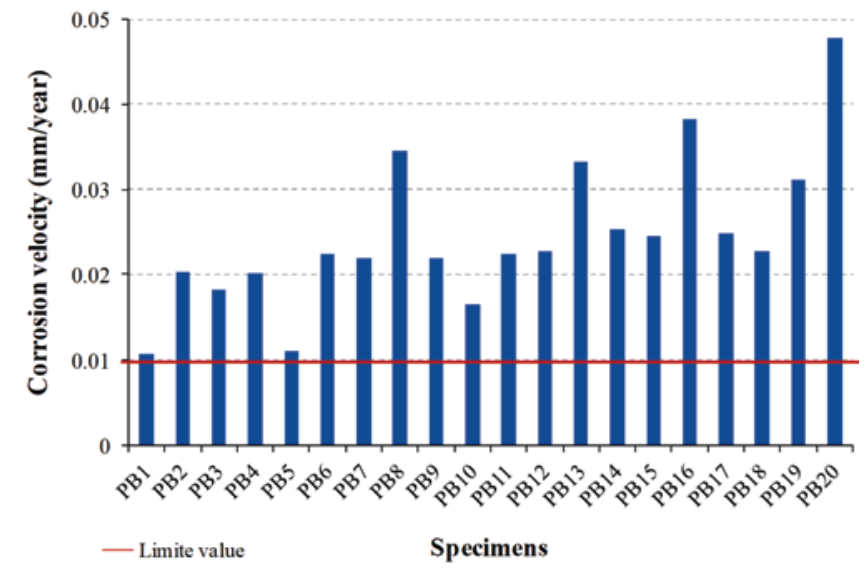

Figure 10

Corrosion velocity of specimens PB1-PB20 

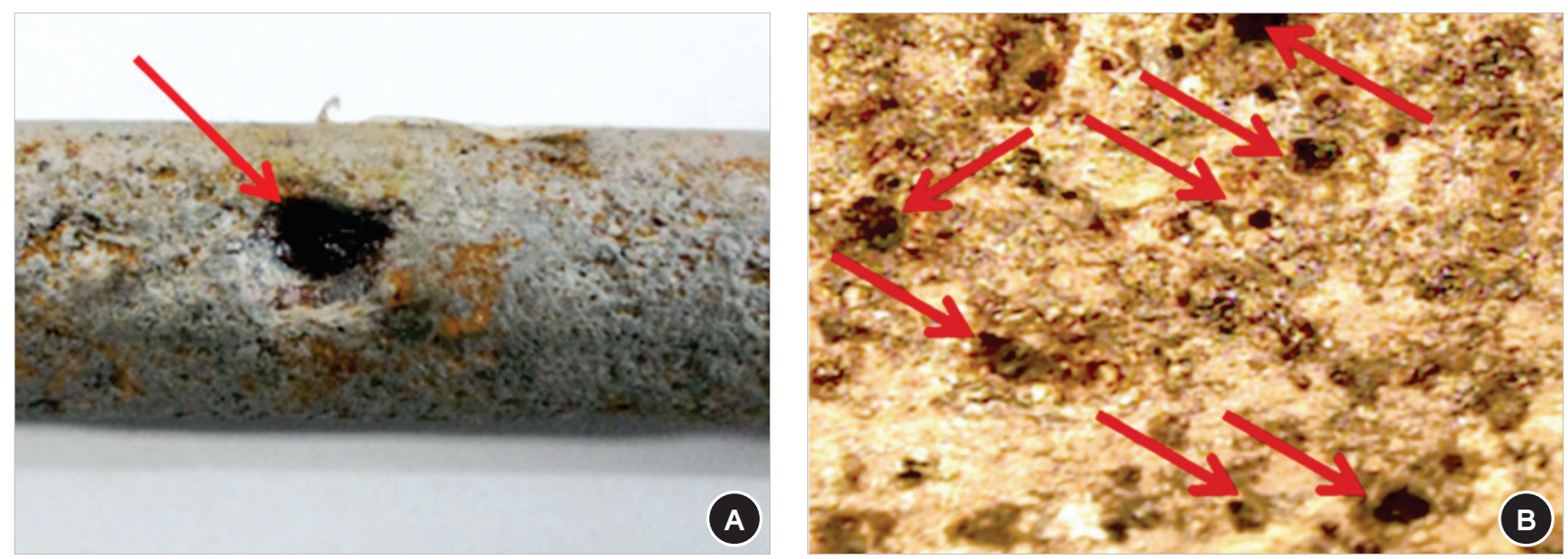

\section{Figure 11}

(a) Pit image obtained by visual inspection; (b) Micrographs showing the presence of pits in a certain region of a test specimen. Magnification of 10x

from power samples removed from the upper part of the foundation block, as presented in Figure 2.

\subsubsection{Mechanical properties, mass loss and smaller diameter of test specimens PB1-PB20}

Figure 12 and 13 shows the relationship between mechanical properties with mass loss and with the smaller diameters of test specimens PB1-PB20, respectively.

According to Figure 12 and $13,25 \%$ of the test specimens (PB1, PB4, PB13, PB14 and PB15) had yield strength over the average value of the reference test specimens BL1-BL5 (dashed). The same percentage was observed regarding the ultimate strength, however not necessarily the same bars (PB4, PB5, PB14, PB15 and PB17).

It must also be highlighted that all test specimens PB1-PB20 fractured right after reaching their ultimate strength, without signals of necking. This behavior is in consonance with studies available in literature $[6,10]$. In this aspect, the presence of pits raised the concentration of tension in the sections of the protruding reinforcing steel. Thus, the tension generated in a given section corroded by pits increases expressively as there is an increase of loading during the test, rapidly reaching its ultimate strength, not being observed signals of necking. Besides, under a chemical perspective, the high concentration of sulfur found in the bars contributes to the decrease of ductility, since the iron sulphide leads to a fragility of the iron.

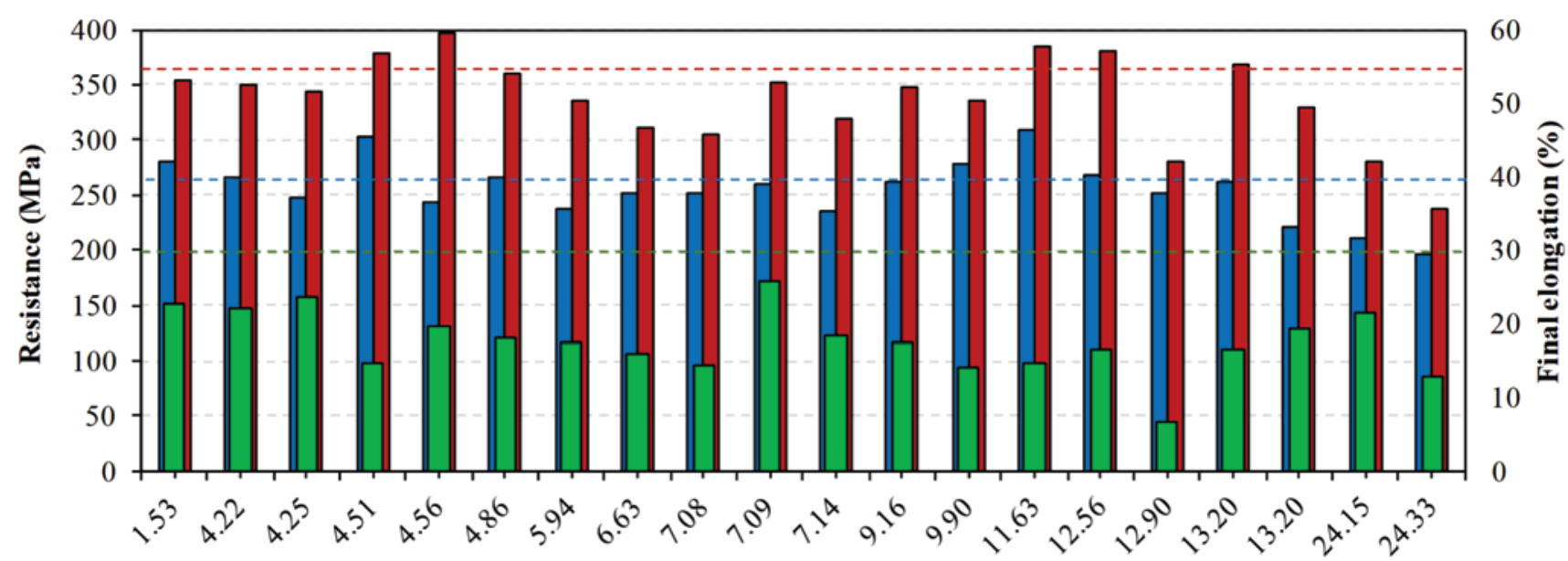

PB1 PB2 2 PB3 1 PB4 PB5 PB6 PB7 PB8 PB9 PB10 PB11 PB12 PB13 PB14 PB15 PB16 PB17 PB18 PB19 PB20

口Yield strength $\quad$ UUltimate strength $\quad$ Final elongation

---. Reference value $\quad-\cdots$ Reference value $\quad-\cdots$ Reference value

Degree of corrosion $(\%)$

Figure 12

Ratio between degree of corrosion and yield strength, ultimate strength and final elongation of test specimens PB1-PB20 


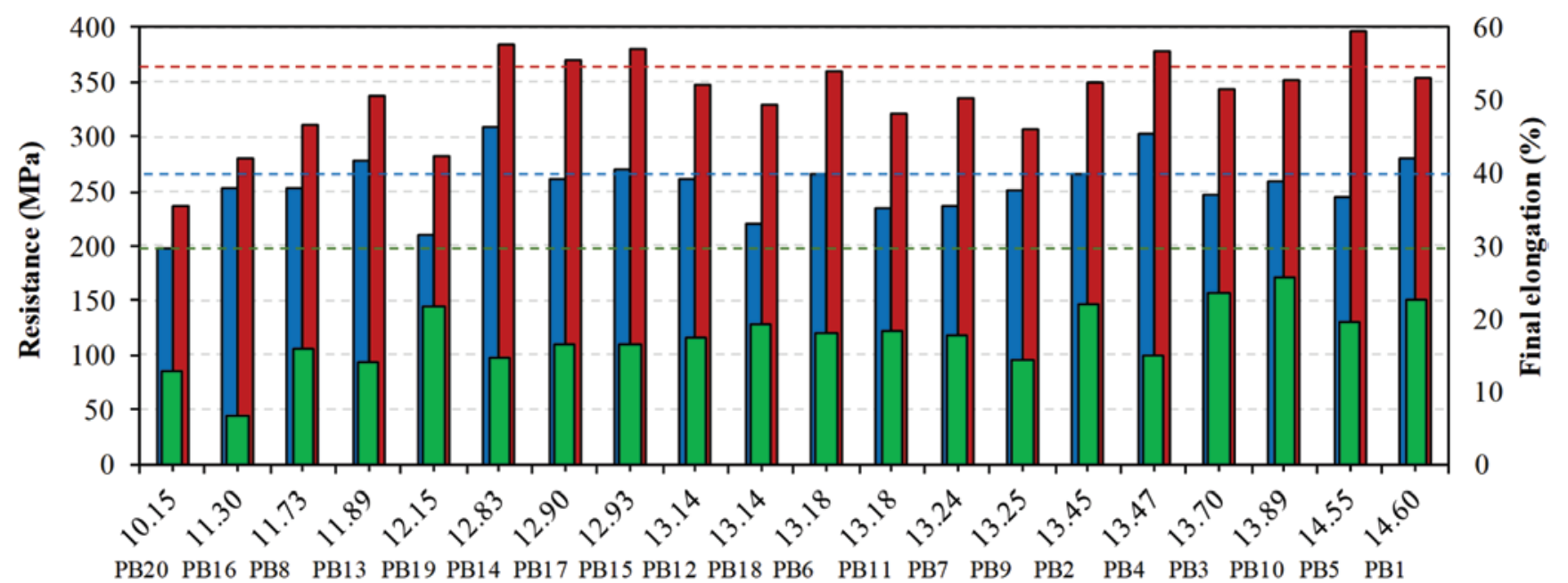

PB20 PB16 PB8 PB13 PB19 PB14 PB17 PB15 PB12 PB18 PB6 PB11 PB7 PB9 PB2 PB4 PB3 PB10 PB5 PB1

aYield strength $\quad$ UUltimate strength $\quad$ Final elongation

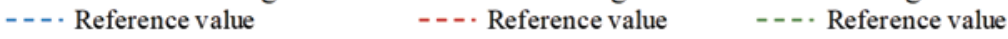

Smallest diameter $(\mathrm{mm})$

Figure 13

Ratio between the smallest diameter with yield strength, ultimate strength and final elongation of the specimens PB1-PB20

A trend of decreasing yield strength and ultimate strength is observed in Figure 12 from a loss of mass of $12 \%$, according to study from Almussallan [12]. For values below the cited one, a progressive trend of decreasing strength is not observed, where even test specimens with loss of mass of $5 \%$ had lower strength values than test specimens with two times the loss of mass. This is clearly observed comparing bars PB4 and PB14, for instance. The justification for this occurrence is related with effects of corrosion by pits to the transversal section of the reinforcement. This means that, in the case of corrosion by pits, expressing the corrosion degree by means of the gravimetric variation of bars may not be enough to represent the variations in strengths, at least until a corrosion degree of $12 \%$.

In Figure 13 it is possible to see an irregular behavior between the smaller diameter with yield and ultimate strengths. However, it is possible to observe a decreasing trend of strength regarding the diameter reduction for values less than $12 \mathrm{~mm}$, representing a loss of transversal section over $20 \%$ regarding the original transversal section. This means that for losses of transversal section over $20 \%$ there is a trend of a progressive decrease of strengths (yield and ultimate) of the corroded reinforcement.

In this sense, the damage made by pits to the transversal section of the corroded reinforcement promotes variations in the position of the axis of the bars along their length, generating eccentricities between the axis position of successive sections of the bars, producing gradients of efforts between those sections when submitted to tension, as also found in Zhu and François [19]. Thus, the effects of corrosion by pits may manifest not only by the loss of the transversal section of protruding reinforcing steel, but also in the geometric change of the axis of their transversal sections, contributing for an irregular behavior and making difficult the framing of a decreasing trend of those mechanical properties for values of section loss under $20 \%$.

Figures 12 and 13 also reveal that the final stretch has an irregular behavior in both cases (loss of mass and smaller diameters), making difficult to express a behavior trend. However, it is possible to state the effects of corrosion are more evident in the decrease of the final stretch of the bars when compared with reference values (dashed lines), agreeing with studies in literature [8, 10]. In this sense, all test specimens, even having a small loss of mass, demonstrated values under the mean stretching of the reference bars (BL1-BL5). This demonstrates that the corrosion effects were more pronounced over the ductility of the corroded reinforcement.

Figure 14 shows the relation between loss of mass and the smaller diameters of test specimens PB1-PB20. Figure 14 shows a trend to decreasing diameters as the loss of mass increases. Besides, it is also possible to observe the presence of two distinct zones. In is interesting to see that zone 2 indicates the occurrence of test

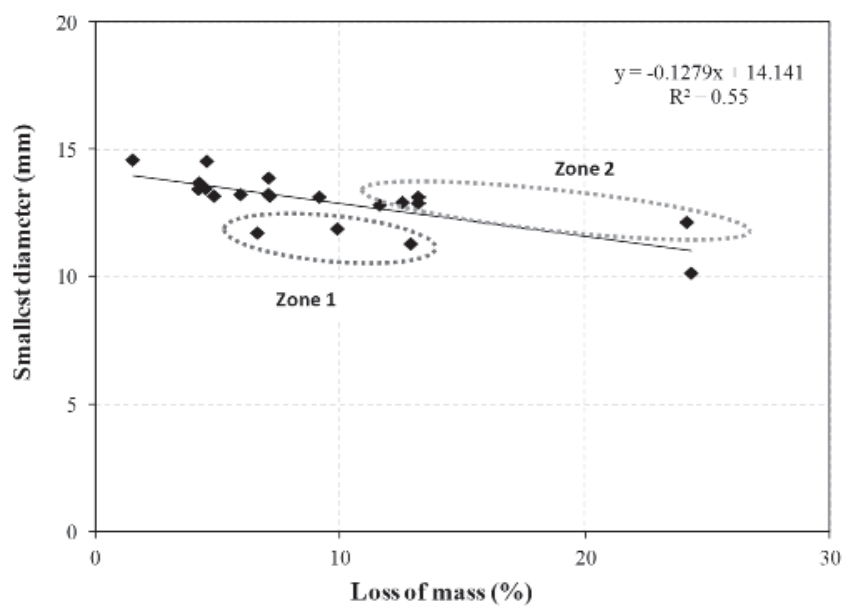

Figure 14

Ratio between smallest diameters and the loss of mass of the test specimens PB1-PB20 
specimens with smaller diameter and greater loss of mass. This fact is associated with corrosion by pits, as verified in Figure 11. Under this strand the pits have as characteristics being able to generate decreases in the transversal section as they go deeper, however without noticeable loss of mass.

\section{Conclusions}

In this paper, an analysis regarding the influence of the corrosion degree by loss of mass and smaller diameters on the mechanical properties of naturally corroded reinforcement in soil was made. Thus, the following conclusions may be highlighted:

- The presence of chlorides in the medium where the protruding reinforcing steel were buried during 60 years was found, its origin being from an external source. This fact justifies the appearance of pits with until $4 \mathrm{~mm}$ of depth in protruding reinforcing steel, impacting, notoriously, the mechanical properties of the protruding reinforcing steel. Besides, the characterization of the soil aggressiveness only by means of its resistance demonstrated to be ineffective.

- The effects of corrosion by pits show that analysis made from the corrosion degree and smaller diameters do not represent a trend of progressive decrease of the mechanical properties of the corroded reinforcement, demonstrating that those parameters are not the more appropriate for analyzing the mechanical properties of corroded reinforcement submitted to tension, since the eccentricities of the section generated by pits are not expressed by the parameters previously mentioned. Thus, concomitantly to this fact, the tension gradients that appear between those successive sections, contributing for the decrease of the mechanical properties of the corroded reinforcement, are not expressed by the corrosion degree and by smaller diameters, justifying the irregularity of behavior observed.

- Corrosion effects are more noticeable regarding the decrease of ductility of bars, considering that no corroded test specimen reached the final stretching value of reference; besides, no necking were observed in bars with corrosion degree over $12 \%$. This demonstrated that structural elements whose degree of corrosion is over $12 \%$ may have sudden collapses.

- Two distinct zones were identified, representing that even test specimens with more loss of mass, not necessarily have smaller diameters. This behavior is characteristic for corrosion by pits, because reduction in the transversal section may be identified as the pits are deeper, however, without necessarily a significant loss of mass.

\section{Acknowledgments}

Authors thank the "Instituto Tecnológico de Aeronáutica - ITA" and the "Coordenação de Aperfeiçoamento de Pessoal de Nível Superior - CAPES".

\section{References}

[1] PAPE, T. M.; MELCHERS, R. E. Performance of 45-year-old corroded prestressed concrete beams. Structures and Buildings, v.166, n.SB10, 2012, p. 547-559.
[2] REHMAN, S.; AL-HADHRAMI, L. M. Web-based national corrosion cost inventory system for Saudi Arabia. Anti-Corrosion Methods and Materials, v.61, n.2, 2013, p. 77-92.

[3] SURNAM, B. Y. R. Prevention and cost of atmospheric corrosion in Mauritius. Anti-Corrosion Methods and Materials, v.60, n.2, 2013, p. 77-83.

[4] MEDEIROS-JUNIOR, R. A.; LIMA, M. G.; BRITO, P. C.; MEDEIROS, M. H. F. Chloride penetration into concrete in an offshore platform-analysis of exposure conditions. Ocean Engineering, v.103, 2015, p.78-87.

[5] PALSSOM, R.; MIRZA, M. S. Mechanical Response of Corroded Steel Reinforcement of Abandoned Concrete Bridge. ACI Structural Journal, v.99, n.2, 2002, p. 157-162.

[6] APOSTOLOPOULOS, C. A.; PAPADAKIS, V. G. Consequences of steel corrosion on the ductility properties of reinforcement bar. Construction and Building Materials, v.22, 2007, p. 2316-2324.

[7] AZAD, A. K.; AHMAD, S.; AZHER, S. A. Residual Strength of Corrosion-Damaged Reinforced Concrete Beams- ACI Materials Journal, v. 104, n.1, 2007, p. 40-47.

[8] FRANÇOIS, R.; KHAN, I.; DANG, V. H. Impact of corrosion on mechanical properties of steel embedded in 27-year-old corroded reinforced concrete beams. Material and Structures, v.46, 2013, p. 889-910.

[9] MEDEIROS-JUNIOR, R. A.; LIMA, M. G.; MEDEIROS, M. H. F.; REAL, L. V. Investigação da resistência à compressão e da resistividade elétrica de concretos com diferentes tipos de cimento, Revista ALCONPAT, v.4, 2014, p.116-132.

[10] APOSTOLOPOULOS, C. A.; DEMIS, S.; PAPADAKIS, V. G. Chloride-induced corrosion of steel reinforcement - Mechanical performance and pit depth analysis. Construction and Building Materials, v. 38, 2013, p. 139-146.

[11] BALESTRA, C. E. T.; LIMA, M. G.; SILVA, A. R.; MEDEIROSJUNIOR, R. A. Corrosion degree effect on nominal and effective strengths of naturally corroded reinforcement. Journal of Materials in Civil Engineering, v. 28, 2016, p. 04016103.

[12] ALMUSALLAN, A. A. Effect of degree of corrosion on the properties of reinforcing. Construction and Building Materials, v.15, 2001, p. 361-368.

[13] APOSTOLOPOULOS, C. A.; PAPADOPOULOS, M. P.; PANTELAKIS, Sp. G. Tensile Behavior of Corroded Reinforcing Steel Bars BSt 500s. Construction and Building Materials, v.20, 2005, p. $782-789$

[14] APOSTOLOPOULOS, C. A.; MICHALOPOULOS, D.; KOUTSOUKOS, P. The corrosion effects on the structural integrity of reinforcing steel. Journal of Materials and Engineering and Performance, v.17, n. 4, 2008, p. 506-516.

[15] ZHANG, W. P.; DAI, H. C.; GU, X. L.; WU, S. N. Effect of Corrosion Pits on Mechanical Properties of Corroded Steel Bars. Earth and Space 2010: Engineering, Science, construction and Operations in Challenging Environments, 2010, p. 3504-3511.

[16] ZHANG, W.; SONG, X.; GU, X.; LI, S. Tensile and fatigue behavior of corroded rebars. Construction and Building Materials, v.34, 2012, p. 409-417.

[17] PAPADOPOULOS, M. P.; APOSTOLOPOULOS, C. A.; ZERVAKI, A. D.; HAIDEMENOPOULOS, G.N. Corrosion of exposed rebars associated mechanical degradation and 
correlation with accelerated corrosion test. Construction and Building Materials, v. 23, n.8, 2011, p. 3367-3374.

[18] APOSTOLOPOULOS, C. A. The influence of corrosion and cross-section diameter on the mechanical properties of B500c steel. Journal of Materials Engineering and Performance, v.18, n.2, 2009, p. 190-195.

[19] ZHU, W.; FRANÇOIS, R. Experimental investigation of the relationship between residual cross-section shapes and the ductility of corroded bars. Construction and Building Materials, v.69, 2014, p. 335-345.

[20] NORHAZILAN, N. M.; NORDIN, Y.; LIM, K. S.; SITI, R. O.; SAFUAN, A. R. A.; NORHAMIMI, M. H. Relationship between soil properties and corrosion of carbon steel. Journal of Applied Science Research, v.8, n.3, 2012, p. 1739-1747.

[21] REVIE, R. W.; UHLIG. H. H. Corrosion and Corrosion Control - An Introduction to Corrosion Science and Engineering. New Jersey, John Wiley \& Sons, Inc., Fourth Edition, 2008.

[22] LOUREIRO, A.; BRASIL, S.; YOKOYAMA, L. Estudo da Corrosividade de Solo Contaminado por Substânias Químicas Através de Ensaios de Perda de Massa e Índice de Steinrath. Corrosão e Protecção de Materiais, v.26, n.4, 2007, p. 113-121 (in Portuguese).

[23] ISMAIL A. I. M.; EI-SHAMY, A. M. Engineering behaviour of soil materials on the corrosion of mild steel. Applied clay science, v. 42, 2009, p. 356-362.

[24] SILVA, J. M; BRASIL, S. L. Critérios de avaliação da corrosividade de solos baseado na sobretensão de hidrogênio. Corrosão e Protecção de Materiais, v.29, n.1, 2010, p. 19-25 (in Portuguese).

[25] PRITChARD, O.; HALLETT, S. H.; FAREWELL, T. S. Soil Corrosivity in the UK - Impacts on Critical Infrastructure. ITRC - Infrastructure Transition Research Consortium, Cranfield University, 2013.

[26] AMERICAN SOCIETY FOR TESTING AND MATERIALS. ASTM G57-06: Standard Test Method for Field Measurement of Soil Resistivity Using the Wenner Four Electrode Method. Pennsylvania, 2012.

[27] NACE INTERNATIONAL - Soil Corrosion. Available in: http://www.nace.org/StarterApps/Wiki/Wiki.aspx?wiki=141; Accessed in jan. 29, 2017.

[28] REUNION INTERNATIONALE DES LABORATORIES ET EXPERTS DES MATERIAUX, SYSTEMES DE CONSTRUCTION ET OUVRAGES. RILEM TC 178-TCM: Testing and Modelling Chloride Penetration in Concrete. Madrid, 2002.

[29] EUROPEAN STANDARDS. EN 14630: Products and systems for the protection and repair of concrete structures test methods - determination of carbonation depth in hardened concrete by the phenolphthalein method. Committee B/517/8, Brussels, 2006.

[30] ASSOCIAÇÃO BRASILEIRA DE NORMAS TÉCNICAS. NBR 6892: Materiais Metálicos - Ensaio de Tração à Temperatura Ambiente. Rio de Janeiro, 2002.

[31] ASSOCIAÇÃO BRASILEIRA DE NORMAS TÉCNICAS. NBR 7480: Aço destinado a armaduras para estruturas de concreto armado - Especificação. Rio de Janeiro, 2007.

[32] MILLS, A. P; HAYWARD, H. W; RADER, L. F. Materials of
Construction - Their Manufacture and Properties. John Wiley \& Sons, Inc. New York, 1939.

[33] CLARK, D. A. R. Engineering Materials - Materials and Structures. Middlesbrough, Blackie \& Son Limited, 1949.

[34] SOUZA, S. A. Composição Química dos Aços, $1^{\circ}$ Edição, São Paulo, Edgard Bluncher, 1989.

[35] AMERICAN SOCIETY FOR TESTING AND MATERIALS. ASTM G1: Standard Practice for Preparing, Cleaning, and Evaluating Corrosion Test. Pennsylvania, 2003.

[36] ULLER, L. \& TROCÓNIS, O. Manual de Inspeccion Evaluation Y Diagnostico de Corrosion em Estructuras de Hormigon Armado. Programa Iberoamericano de Ciencia y Tecnológia para el Desarrollo - Rio de Janeiro: CYTED, 1997.

[37] CEMCO. Durabilidad del Hormigón y Evaluation de Estructuras Corroídas. Instituto de Ciências de la Construccíon Eduardo Torroja, CSIC, 2001.

[38] BERTOLINI, L. Materiais de construção: Patologia, reabilitação e prevenção. Oficina de Textos. Rio de Janeiro, 2010. 